\title{
Interpretative Structural Modelling on Generation Mechanism of Train Operation Conflicts in High Speed Railway
}

\author{
Tao Wang ${ }^{1,2}$, Kang Huang ${ }^{1,2, *}$, Xiaoli Song ${ }^{1,2}$, Zhenyi Wang ${ }^{1,2}$ \\ ${ }^{1}$ Signal and Communication Research institute, China Academy of Railway Sciences Co., Beijing 100081, China \\ ${ }^{2}$ Beijing Hua-Tie Information Technology Development Co., Beijing 100081, China
}

Corresponding Author Email: 08114212@bjtu.edu.cn

https://doi.org/10.18280/ijsse.100414

Received: 9 April 2020

Accepted: 5 July 2020

\section{Keywords:}

high-speed railway (HSR), interpretative structural modelling (ISM), train operation conflicts (TOCs), generation mechanism

\begin{abstract}
To detect and mitigate the operation conflicts of high-speed trains, it is critical to clarify the generation mechanism of train operation conflicts (TOCs) in high speed railway (HSR). Taking train delays as the precondition of the TOCs, this paper sorts out the main causes of the TOCs into four aspects, namely, equipment facilities, human behaviour, external environment, and organization management, and obtains a total of direct and indirect impact factors for HSR TOCs. Then, the interpretative structural modelling (ISM) was adopted to construct the adjacency matrix between these factors, and calculate the reachability matrix. On this basis, a directed hierarchical graph was plotted for the TOC causes based on the hierarchical relationship between the factors. The results show that HSR TOCs are directly caused by equipment facilities, transport organizations, and dispatcher professionality, and indirectly induced by natural environment, equipment operating environment, unexpected passenger flow, as well as the psychological quality, educational level, and years of service of dispatchers; in addition, the working environment, and the management of equipment and dispatchers are the deep-seated reasons for the TOCs. The research results provide new insights into the intelligent dispatching command of the HSR.
\end{abstract}

\section{INTRODUCTION}

Train operation conflicts (TOCs) refer to scenarios that the technical equipment involved in train operations or the organization of train operations fail to meet the operational requirements, owing to the interference of various uncertainties in train operations. The common conflicts in train operations include the conflict between train operation and resource utilization, the lack of coordination in transport organization, and the resource competition between different trains $[1,2]$.

The handling of TOCs is the most complex and important scheduling task of dispatchers. In essence, the scheduling aims to resolve the potential TOCs. If not resolved timely and reasonably, TOCs will lead to train collisions, causing casualties or direct economic loss [3-5]. Therefore, conflict management has become a research hotspot in railway traffic scheduling [6].

The TOC management of high-speed railway (HSR) mainly involves the analysis of generation mechanism, detection, resolution and other aspects of conflicts [7-14]. Among them, the analysis of generation mechanism is the foundation of the TOC management. Once the generation mechanism is clear, it will be more effective to detect and resolve the conflicts.

Many scholars have probed into the management of the TOC. For instance, Fay et al. classified the TOCs into different categories and identified the causes of TOCs in each class, pointing out that the TOCs, as the result of resource competition, are the most important and direct reason for train delays [15-18]. Wen et al. [19] investigated the interferences in train operations and the utilization of redundant time, studied the TOC mechanism of HSR, and established the recursion process of HSR train operation state, under random disturbance and redundant time. Tang et al. [20] analysed the formation mechanism and influence of soft TOCs in train operation diagram, and suggested solving the soft TOCs through integrated simulation of traction power supply and train groups. Wang et al. [21] explored the models and algorithms of conflict detection and scheduling optimization of HSR train operations, and created a train movement prediction model with conflict resolution under model predictive control (MPC). With the aid of fault tree analysis (FTA), Wei et al. [22] set up a fault tree for the collisions between medium and low speed maglev trains, and calculated the minimal cut set, the minimal path set, and the structure importance coefficient of the basic events.

The above studies provide a detailed illustration of TOC causes, shedding light on how to deal with TOCs. However, most of them emphasize on a single or several independent factors over the entire system. In fact, the TOCs often have multiple mutually influencing causes. To make up for the gap, this paper attempts to identify the main causes of the TOCs from various causes, and find out the direct, indirect, and deepseated causes of the TOCs through interpretive structural modelling (ISM) of the TOCs. The results provide a scientific reference for HSR TOC management.

The remainder of this paper is organized as follows: Section 2 outlines the types of TOCs and their causes; Section 3 presents the ISM and its implementation steps; Section 4 establishes the interpretive structural model of the TOCs; 
Section 5 puts forward the conclusions and sums up the contributions of this research.

\section{TYPES OF TOCS AND THEIR CAUSES}

\subsection{Types of TOCs}

The TOCs can be categorized into different classes, depending on the criteria and methods [23]. Based on the subjects and spatiotemporal features, the TOCs can be divided into the conflicts between trains, the conflicts between train operation and equipment utilization, and the conflicts between train operation and operation organization. Specifically, the conflicts between trains can be subdivided into the conflict between interval times and that between station ranges; the conflicts between train operation and equipment utilization can be further split into the conflict between arrival and starting line utilizations, that between operation and maintenance, and that between the connection durations of electric multiple units (EMU); the conflicts between train operation and operation organization can be decomposed into the time conflict between train operation and passenger transfer, and that between cross-line train entering the HSR line and other trains.

\subsection{Causes of TOCs}

According to the data on train delays [24-26], there are four major sources of the TOCs: equipment facilities, human behaviour, external environment, and organization and management.

The failure and performance degradation of the following equipment facilities are prone to cause train delays: the EMU, communication signals, lines, power supply systems, rescue equipment, etc. These factors might not result in traffic accidents, but will disrupt the traffic, increasing the probability of the TOCs.
Human behaviour refers to incorrect dispatching command, mainly the improper command of decision-makers or the maloperations by operators. Human behaviour is easily influenced by such factors as professional qualification, educational level, psychological factors, and working years.

The external environment covers two aspects: natural environment and manmade environment. Natural environment includes inclement weather conditions (typhoon, thunderstorms, and hail), natural disasters (flood and earthquake), and line damages induced by debris flow, landslide, and collapse. The manmade environment includes the working environment of the dispatchers, the operating environment of equipment and sudden factors like unexpected traffic flow.

Organization management consists of management mechanism, transportation organization, equipment management, and personnel management. Among them, transportation organization, focusing on the defects of dispatching command technology, is the key difficulty in the handling of TOCs [27].

The above four categories were refined into 15 correlated and interactive impact factors (Table 1). The directed connection between these factors are described in Figure 1.

Table 1. The classification of impact factors of the TOCs

\begin{tabular}{cc}
\hline Type & Factors \\
\hline $\begin{array}{c}\text { Equipment } \\
\text { facilities }\end{array}$ & $\begin{array}{c}\text { EMU }\left(S_{1}\right) \text {, communication signal system }\left(S_{2}\right) \text {, line } \\
\left(S_{3}\right) \text {, power supply system }\left(S_{4}\right) \text { and rescue equipment } \\
\left(S_{5}\right)\end{array}$ \\
$\begin{array}{c}\text { Human } \\
\text { behaviour }\end{array}$ & $\begin{array}{c}\text { Educational level }\left(S_{6}\right) \text {, psychological factors }\left(S_{7}\right), \\
\text { working years }\left(S_{8}\right) \text { and professional qualification }\left(S_{9}\right)\end{array}$ \\
$\begin{array}{c}\text { External } \\
\text { environment }\end{array}$ & $\begin{array}{c}\text { Natural environment }\left(S_{10}\right) \text {, working environment }\left(S_{11}\right), \\
\text { equipment operation environment }\left(S_{12}\right) \text { and unexpected } \\
\text { traffic flow }\left(S_{13}\right)\end{array}$ \\
$\begin{array}{c}\text { Organization } \\
\text { management }\end{array}$ & $\begin{array}{c}\text { Management mechanism }\left(S_{14}\right) \text {, transportation } \\
\text { organization }\left(S_{15}\right), \text { equipment management }\left(S_{16}\right) \text { and } \\
\text { personnel management }\left(S_{17}\right)\end{array}$ \\
\hline
\end{tabular}

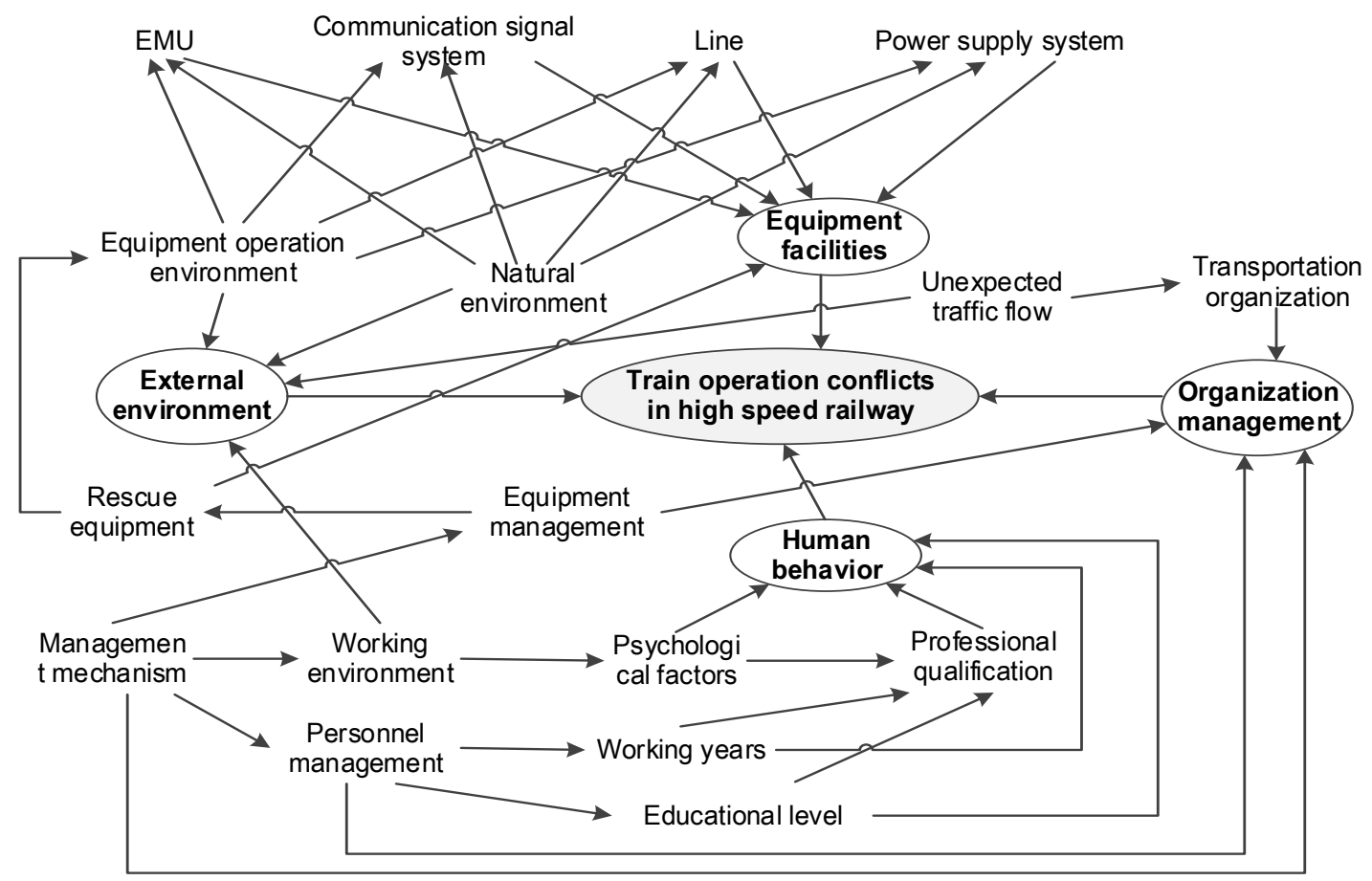

Figure 1. The directed connections between the 15 impact factors 


\section{THE ISM}

The ISM was proposed by Warfield in 1973 to analyse complex socioeconomic systems [28, 29]. Under the principle of associative matrix in graph theory, the ISM decomposes the complex system into several subsystems, creating an intuitive and well-structured hierarchical model. This approach boasts good adaptability in analysis on the factors, safety, and risk of complex systems [30]. In general, the ISM is implemented in four steps:

Step 1. Generate adjacency matrix $A$

Let $S=\left\{S_{1}, S_{2}, \ldots, S_{\mathrm{n}}\right\}$ be the $n$ factors affecting the evaluation objectives in the system. Then, the adjacency matrix $A$ can be established based on these factors. Factor $a_{i j}$ in $A$ refers to the directed connection between any two factors:

$$
A=\left\{a_{i j}\right\}_{n \times n^{\prime}}, a_{i j}=\left\{\begin{array}{l}
1, S_{i} \text { is related to } S_{j} \\
0, S_{i} \text { is unrelated to } S_{j}
\end{array}\right.
$$

Step 2. Calculate reachability matrix $R$

Taking the adjacency matrix $A$ and unit matrix $I$ as the exponentiation of $A+I$, the following formula can be established through Boolean operations:

$$
A+I \neq(A+I)^{2} \neq \cdots(A+I)^{r}=(A+I)^{r+1}=R
$$

where, $R=(A+I)^{r}$ is reachability matrix. Each element $s_{i j}$ in $R$ reflects whether there are reachable paths between factors $i$ and $j$, revealing both direct and indirect connections between the various factors in the system.

Step 3. Division of hierarchical relationship

Based on reachability matrix $R$, reachable set $M\left(S_{i}\right)$ and antecedent set $N\left(S_{i}\right)$ can be obtained under the following conditions of factor set $L_{i}$ :

$$
M\left(S_{i}\right) \cap N\left(S_{i}\right)=M\left(S_{i}\right)
$$

According to the definitions of reachable set and antecedent set, the top-level factors of directed graph of $L_{i}$ are confirmed. Then, the rows and columns corresponding to the factors in $L_{i}$ are removed from the original reachability matrix $\mathrm{R}$, and the new top-level factors are found from the remaining reachable matrix. Finally, the set of the most advanced factors are identified at all levels.

Step 4. Plotting a hierarchical directed graph

According to the hierarchical relationship, the factors are sorted from top to bottom, and the connection between every two factors is expressed with a directed segment, thus obtaining the hierarchical directed graph of the system.

Compared with the pairwise relationship between system factors, the hierarchical directed graph obtained by the ISM presents an intuitive picture of the system structure. As a result, the ISM is an important tool for analysing the hierarchical relationship of system factors and the influence of factors on system functions.

\section{ISM ANALYSIS OF TOCS}

\subsection{Establishing the adjacency matrix}

The ISM was carried out the analyse the causes of the TOCs in Table 1. Then, the following adjacency matrix can be established according to Figure 1:

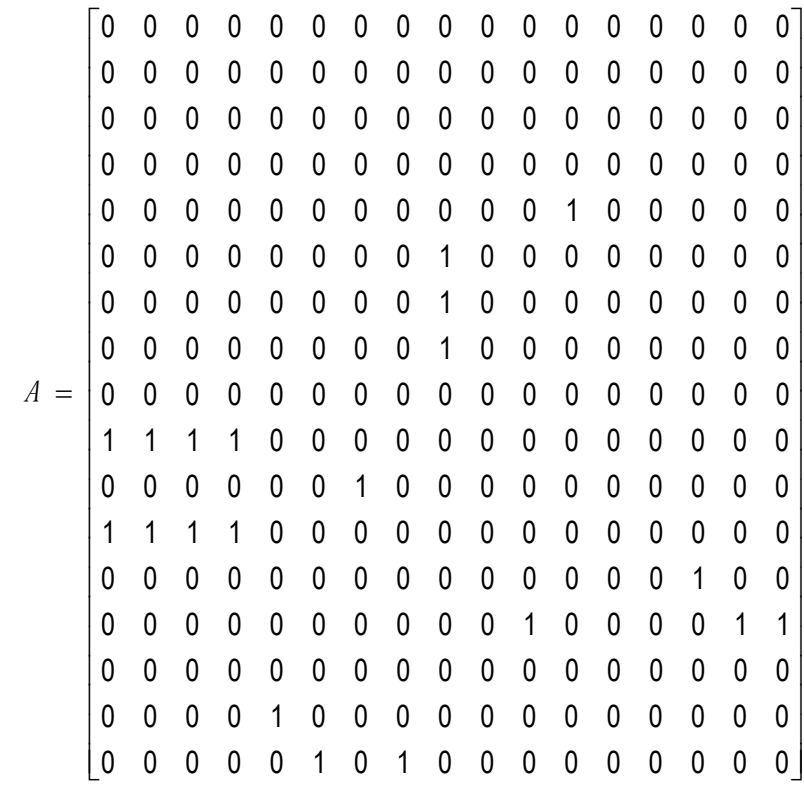

\subsection{Calculating the reachability matrix}

Through exponentiation, the reachability matrix $R=(A+$ $I)^{3}$ can be derived from $r=3$, and $A+I \neq(A+I)^{2} \neq$ $(A+I)^{3} \neq(A+I)^{4}$ :

$$
R=\left[\begin{array}{lllllllllllllllll}
1 & 0 & 0 & 0 & 0 & 0 & 0 & 0 & 0 & 0 & 0 & 0 & 0 & 0 & 0 & 0 & 0 \\
0 & 1 & 0 & 0 & 0 & 0 & 0 & 0 & 0 & 0 & 0 & 0 & 0 & 0 & 0 & 0 & 0 \\
0 & 0 & 1 & 0 & 0 & 0 & 0 & 0 & 0 & 0 & 0 & 0 & 0 & 0 & 0 & 0 & 0 \\
0 & 0 & 0 & 1 & 0 & 0 & 0 & 0 & 0 & 0 & 0 & 0 & 0 & 0 & 0 & 0 & 0 \\
1 & 1 & 1 & 1 & 1 & 0 & 0 & 0 & 0 & 0 & 0 & 1 & 0 & 0 & 0 & 0 & 0 \\
0 & 0 & 0 & 0 & 0 & 1 & 0 & 0 & 1 & 0 & 0 & 0 & 0 & 0 & 0 & 0 & 0 \\
0 & 0 & 0 & 0 & 0 & 0 & 1 & 0 & 1 & 0 & 0 & 0 & 0 & 0 & 0 & 0 & 0 \\
0 & 0 & 0 & 0 & 0 & 0 & 0 & 1 & 1 & 0 & 0 & 0 & 0 & 0 & 0 & 0 & 0 \\
0 & 0 & 0 & 0 & 0 & 0 & 0 & 0 & 1 & 0 & 0 & 0 & 0 & 0 & 0 & 0 & 0 \\
1 & 1 & 1 & 1 & 0 & 0 & 0 & 0 & 0 & 1 & 0 & 0 & 0 & 0 & 0 & 0 & 0 \\
0 & 0 & 0 & 0 & 0 & 0 & 1 & 0 & 1 & 0 & 1 & 0 & 0 & 0 & 0 & 0 & 0 \\
1 & 1 & 1 & 1 & 0 & 0 & 0 & 0 & 0 & 0 & 0 & 1 & 0 & 0 & 0 & 0 & 0 \\
0 & 0 & 0 & 0 & 0 & 0 & 0 & 0 & 0 & 0 & 0 & 0 & 1 & 0 & 1 & 0 & 0 \\
1 & 1 & 1 & 1 & 1 & 1 & 1 & 1 & 1 & 0 & 1 & 1 & 0 & 1 & 0 & 1 & 1 \\
0 & 0 & 0 & 0 & 0 & 0 & 0 & 0 & 0 & 0 & 0 & 0 & 0 & 0 & 1 & 0 & 0 \\
1 & 1 & 1 & 1 & 1 & 0 & 0 & 0 & 0 & 0 & 0 & 1 & 0 & 0 & 0 & 1 & 0 \\
0 & 0 & 0 & 0 & 0 & 1 & 0 & 1 & 1 & 0 & 0 & 0 & 0 & 0 & 0 & 0 & 1
\end{array}\right]
$$

\subsection{Division of hierarchical relationship}

Firstly, the reachability set $M\left(S_{i}\right)$ and antecedent set $N\left(S_{i}\right)$ were obtained from reachability matrix $R$. Then, the intersection $L_{i}$ between the two sets was obtained. The calculating results of the first level are shown in Table 2 . The calculating results of the other levels are displayed in Tables 3 to 6 .

As shown in Table 2, factors of $L_{i}=M\left(S_{i}\right) \cap N\left(S_{i}\right)$ include $S_{1}, S_{2}, S_{3}, S_{4}, S_{9}$ and $S_{15}$. Thus, these factors are the top level of system. The factors of the first level can be expressed as $L_{1}=\{1,2,3,4,9,15\}$. Similarly, $L_{2}=$ $\{6,7,8,10,12,13\}, L_{3}=\{5,11,17\}, L_{4}=\{16\}$ and $L_{5}=\{14\}$ can be obtained. 
Table 2. The reachability and antecedent set of the first level

\begin{tabular}{cccc}
\hline$i$ & Reachability set & Antecedent set & Intersection \\
& $M\left(S_{i}\right)$ & $N\left(S_{i}\right)$ & $L_{i}$ \\
\hline 1 & 1 & $1,5,10,12,14,16$ & 1 \\
2 & 2 & $2,5,10,12,14,16$ & 2 \\
3 & 3 & $3,5,10,12,14,16$ & 3 \\
4 & 4 & $4,5,10,12,14,16$ & 4 \\
5 & $1,2,3,4,5,12$ & $5,14,16$ & 5 \\
6 & 6,9 & $6,14,17$ & 6 \\
7 & 7,9 & $7,11,14$ & 7 \\
8 & 8,9 & $8,14,17$ & 8 \\
9 & 9 & $6,7,8,9,11,14,17$ & 9 \\
10 & $1,2,3,4,10$ & 10 & 10 \\
11 & $7,9,11$ & 11,14 & 11 \\
12 & $1,2,3,4,12$ & $5,12,14,16$ & 12 \\
13 & 13,15 & 13 & 13 \\
14 & $1,2,3,4,5,6,7,8,9,11,12$ & 14 & 14 \\
15 & $, 14,16,17$ & 13,15 & 15 \\
16 & $1,2,3,4,5,12,16$ & 14,16 & 16 \\
17 & $6,8,9,17$ & 14,17 & 17 \\
\hline
\end{tabular}

Table 3. The reachability and antecedent set of the second level

\begin{tabular}{cccc}
\hline$i$ & Reachability set $M\left(S_{i}\right)$ & Antecedent set & Intersection \\
& $N\left(S_{i}\right)$ & $L_{i}$ \\
\hline 5 & 5,12 & $5,14,16$ & 5 \\
6 & 6 & $6,14,17$ & 6 \\
7 & 7 & $7,11,14$ & 7 \\
8 & 8 & $8,14,17$ & 8 \\
10 & 10 & 10 & 10 \\
11 & 7,11 & 11,14 & 11 \\
12 & 12 & $5,12,14,16$ & 12 \\
13 & 13 & 13 & 13 \\
14 & $5,6,7,8,11,12,14,16,17$ & 14 & 14 \\
16 & $5,12,16$ & 14,16 & 16 \\
17 & $6,8,17$ & 14,17 & 17 \\
\hline
\end{tabular}

Table 4. The reachability set and antecedent set of the third level

\begin{tabular}{cccc}
\hline \multirow{2}{*}{$i$} & Reachability set & Antecedent set & Intersection \\
& $M\left(S_{i}\right)$ & $N\left(S_{i}\right)$ & $L_{i}$ \\
\hline 5 & 5 & $5,14,16$ & 5 \\
11 & 11 & 11,14 & 11 \\
14 & $5,11,14,16,17$ & 14 & 14 \\
16 & 5,16 & 14,16 & 16 \\
17 & 17 & 14,17 & 17 \\
\hline
\end{tabular}

Table 5. The reachability set and antecedent set of the fourth level

\begin{tabular}{cccc}
\hline \multirow{2}{*}{$i$} & Reachability set & Antecedent set & Intersection \\
& $M\left(S_{i}\right)$ & $N\left(S_{i}\right)$ & $L_{i}$ \\
\hline 14 & 14,16, & 14 & 14 \\
16 & 16 & 14,16 & 16 \\
\hline
\end{tabular}

Table 6. The reachability set and antecedent set of the fifth level

\begin{tabular}{cccc}
\hline \multirow{2}{*}{$i$} & Reachability set & Antecedent set & Intersection \\
& $M\left(S_{i}\right)$ & $N\left(S_{i}\right)$ & $L_{i}$ \\
\hline 14 & 14 & 14 & 14 \\
\hline
\end{tabular}

\subsection{Plotting hierarchical directed graph}

According to the results of hierarchical relationship, some levels were integrated to obtain a hierarchical directed graph of the causes for the TOCs in HSR (Figure 2).

\subsection{Cause analysis}

As shown in Figure 2, the cause system of HSR TOCs is a complex multi-layer system. The TOC causes can be divided into three levels:

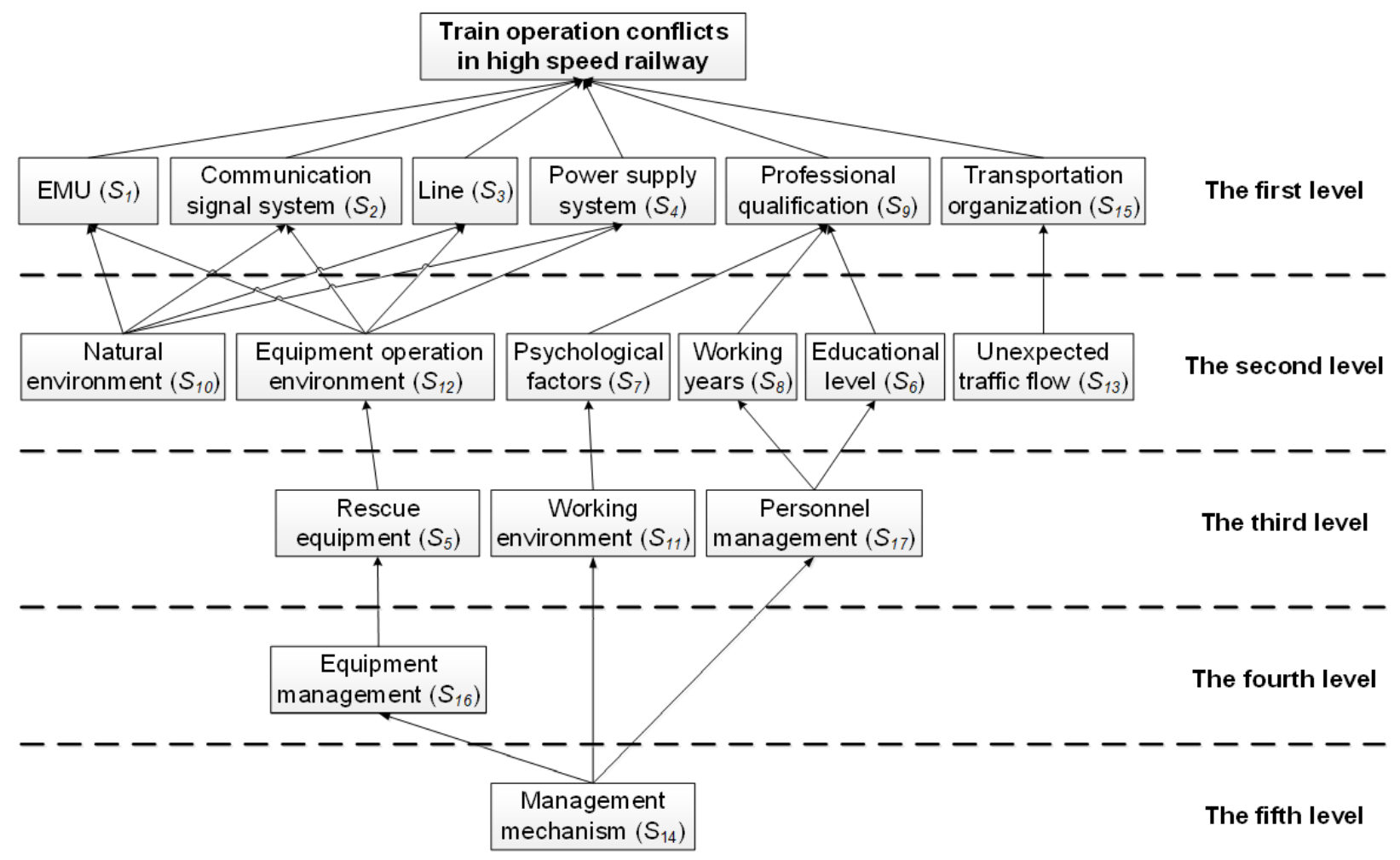

Figure 2. The hierarchical directed graph of the causes of the TOCs 
(1) There are six direct impact factors on the top level, namely, EMU $\left(S_{1}\right)$, communication signal system $\left(S_{2}\right)$, line $\left(S_{3}\right)$, power supply system $\left(S_{4}\right)$, professional qualification $\left(S_{9}\right)$, and transportation organization $\left(S_{15}\right)$. These factors can be interpreted as the bad hardware state, the unsafe human behaviours, and the defects of scheduling command software. The prevention of the TOCs induced by these factors require a multi-pronged approach.

The EMU, communication signal system, line, power supply system, and other hardware are the foundation of train operations. The operation states of these hardware directly bear on the service quality of HSR. Owing to the particularity of railway transport, the failure or performance degradation of hardware could easily lead to TOCs, bringing noneligible economic loss and social impact. Human are the subject of dispatching command, while transportation organization is the soft tool of dispatching command. Any mistake in human behaviour or transportation organization may cause TOCs.

(2) There are seven indirect impact factors on the intermediate layer, such as natural environment $\left(S_{10}\right)$, equipment operating environment $\left(S_{12}\right)$, rescue equipment $\left(S_{5}\right)$, psychological factors $\left(S_{7}\right)$, working years $\left(S_{8}\right)$, education level $\left(S_{6}\right)$, and unexpected passenger flow $\left(S_{13}\right)$.

These impact factors belong to train operation environment and adverse human behaviours. To ensure the normal use of the hardware system, it is necessary to improve the early warning of natural disasters, while maintaining the operational environment of the equipment and keeping the good state of rescue equipment; to reduce errors of dispatchers, it is necessary to improve physical quality, technical level, and work experience of personnel in all aspects; to guarantee the normal transportation organization, it is necessary to monitor real-time traffic, forecast the future passenger flow, complete early warning of unexpected traffic flow, and formulate pertinent emergency measures.

(3) There are four indirect impact factors on the bottom layer, including management system $\left(S_{14}\right)$, equipment management $\left(S_{16}\right)$, personnel management $\left(S_{17}\right)$, and the working environment $\left(S_{11}\right)$.

The first three factors are subordinates of the organization management, while the last one falls in the category of external environment. This means the eradication of the TOCs relies on strengthening the TOC management, reinforcing the management of equipment and scheduling, and improving working conditions.

\section{CONCLUSIONS}

(1) The TOCs are directly caused by failure and performance degradation of the hardware system, software system, and human factor system. The hardware system includes the EMU, communication system, signal, lines, and power supply system; the software system mainly involves the dispatching command technology for transport organization; the human factor system centres on the professional quality of dispatching command personnel.

(2) In terms of the hardware system, the impact factors include the natural environment, equipment operating environment, rescue equipment, and equipment management. To ensure its reliable use, the equipment should be inspected and maintained regularly during the train operations. In addition, it is necessary to strengthen the early warning of natural disasters, and enhance the reliability of the equipment operations.

(3) In terms of software system, advanced technology of transportation organization is helpful to reduce the interference of unexpected passenger flow in train operations and improve the punctuality of trains.

(4) In terms of human factor system, the professional quality of dispatchers is influenced by such factors as psychology, educational level, working years, working environment, and dispatcher management. To reduce the faults of dispatching personnel and ensure the reliability of train operations, it is important to improve the overall quality of dispatching personnel and provide them with a good working environment.

\section{ACKNOWLEDGEMENTS}

The work is supported by the Project of High-speed Rail Joint Fund "Research on Theory and Method of Intelligent Dispatching of High-speed Railway Based on Cooperative Command (Grant No.: U1834211)".

\section{REFERENCES}

[1] Wen, C. (2011). Train operation conflict management research status of high-speed railways. Journal of Transportation Security, 4(3): 231-246. https://doi.org/10.1007/s12198-011-0069-0

[2] Caimi, G., Chudak, F., Fuchsberger, M., Laumanns, M., Zenklusen, R. (2011). A new resource-constrained multicommodity flow model for conflict-free train routing and scheduling. Transportation Science, 45(2): 212-227. https://doi.org/10.1287/trsc. 1100.0349

[3] Zhang, F.Q. (2020). Fuzzy decision adjustment of train operation plan for high-speed rail network based on multi-objective optimization. Journal Européen des Systèmes Automatisés, 53(1): 131-136. https://doi.org/10.18280/jesa.530116

[4] Andersson, E. (2014). An economic evaluation of the Swedish prioritisation rule for conflict resolution in train traffic management. Procedia-Social and Behavioral Sciences, 111: 634-644. https://doi.org/10.1016/j.sbspro.2014.01.097

[5] Sakhala, N.K., Tanksale, A., Jha, J.K. (2019). Path anticipation and prioritised conflict-free train rescheduling on a linear network. International Journal of Operational Research, 36(4): 496-517. https://doi.org/10.1504/IJOR.2019.104054

[6] Sahin, I. (1999). Railway traffic control and train scheduling based on inter-train conflict management. Transportation Research Part B: Methodological, 33(7): 511-534. https://doi.org/10.1016/S0191-2615(99)000041

[7] Oh, S.M., Hong, S.H., Choi, I.C. (2004). Railway conflict detection and resolution in the Korean railway system. WIT Transactions on The Built Environment, 74: 675-684. https://doi.org/10.2495/CR040681

[8] Dariano, A., Pranzo, M., Hansen, I. A. (2007). Conflict resolution and train speed coordination for solving realtime timetable perturbations. IEEE Transactions on Intelligent Transportation Systems, 8(2): 208-222. https://doi.org/10.1109/TITS.2006.888605

[9] Zhuang, H., Feng, L., Wen, C., Peng, Q., Tang, Q. (2016). High-speed railway train timetable conflict prediction 
based on fuzzy temporal knowledge reasoning. Engineering, 2(3): 366-373. https://doi.org/10.1016/J.ENG.2016.03.019

[10] Sun, Y., Cao, C., Wu, C. (2014). Multi-objective optimization of train routing problem combined with train scheduling on a high-speed railway network. Transportation Research Part C: Emerging Technologies, 44(7): 1-20. https://doi.org/10.1016/j.trc.2014.02.023

[11] Pascal, F., Kammoun, A. (2016). Robust random matrix theory and applications to radar detection. Traitement $\mathrm{Du}$ Signal, 33(2-3): 321-349. https://doi.org/10.3166/ts.33.321-349

[12] Olivier-Maget, N., Hetreux, G. (2016). Fault detection and isolation for industrial risk prevention. Journal Européen des Systèmes Automatisés, 49(4-5): 537-557. https://doi.org/10.3166/JESA.49.537-557

[13] Kang, G. (2016). Influence and control strategy for local settlement for high-speed railway infrastructure. Engineering, 2(3): 374-379. https://doi.org/10.1016/J.ENG.2016.03.014

[14] Besinovic, N., Goverde, R.M., Quaglietta, E., Roberti, R. (2016). An integrated micro-macro approach to robust railway timetabling. Transportation Research Part B: Methodological, $\quad 87(5)$ : $14-32$ http://dx.doi.org/10.1016/j.trb.2016.02.004

[15] Fay, A. (2000). A fuzzy knowledge-based system for railway traffic control. Engineering Applications of Artificial Intelligence, 13(6): 719-729. https://doi.org/10.1016/S0952-1976(00)00027-0

[16] Makkinga, F., Metselaar, S. (2000). Automatic conflict detection and decision support for optimal usage of railway infrastructure. WIT Transactions on The Built Environment, $\quad 50$ 1057-1064. https://doi.org/10.2495/CR001031

[17] Törnquist, J. (2005). Computer-based decision support for railway traffic scheduling and dispatching: A review of models and algorithm. 5th Workshop on Algorithmic Methods and Models for Optimization of Railways (ATMOS'05), Palma de Mallorca, Spain. https://doi.org/10.4230/OASIcs.ATMOS.2005.659

[18] Mazzarello, M., Ottaviani, E. (2007). A traffic management system for real-time traffic optimization in railways. Transportation Research Part B: Methodological, 41(2): 246-274. https://doi.org/10.1016/j.trb.2006.02.005

[19] Wen, C., Peng, Q.Y., Chen, Y.H. (2012). Running conflict mechanism of high-speed railway train. Journal of Traffic and Transportation Engineering, 12(2): 119126

[20] Tang, J.J., Zhou, L.S., Ran, F., Chen, L.C. (2012)
Research on train scheduling for high-speed railway lines based on soft conflict adjustment. Journal of the China $\begin{array}{lll}\text { Railway } & \text { Society, } & 34(4):\end{array}$ https://doi.org/10.3969/j.issn.1001-8360.2012.04.001

[21] Wang, Z., Zhou, Y., Liu, D. (2018). Models and algorithms of conflict detection and scheduling optimization for high-speed train operations based on MPC. Journal of Control Science and Engineering, 3473175. https://doi.org/10.1155/2018/3473175

[22] Wei, Q.C., Pan, Z.H., Chu, Z.J., Li M. (2019). Fault tree analysis in operation accident of medium and low speed maglev. Urban Mass Transit, 2(21): 25-29.

[23] Wen, C. (2010). Prediction methods of train operation conflict for high-speed railway. Journal of Transportation Security, 3(4): 275-286. https://doi.org/10.1007/s12198-010-0052-1

[24] Corman, F., Kecman, P. (2018). Stochastic prediction of train delays in real-time using Bayesian networks. Transportation Research Part C: Emerging Technologies, 95(10): 599-615. https://doi.org/10.1016/j.trc.2018.08.003

[25] Xu, P., Corman, F., Peng, Q. (2016). Analyzing railway disruptions and their impact on delayed traffic in Chinese high-speed railway. IFAC-Papers Online, 49(3): 84-89. https://doi.org/10.1016/j.ifacol.2016.07.015

[26] Nair, R., Hoang, T.L., Laumanns, M., Chen, B., Cogill, R., Szabó, J., Walter, T. (2019). An ensemble prediction model for train delays. Transportation Research Part C: Emerging Technologies, 104(7): 196-209. https://doi.org/10.1016/j.trc.2019.04.026

[27] Min, Y.H., Park, M.J., Hong, S.P., Hong, S.H. (2011). An appraisal of a column-generation-based algorithm for centralized train-conflict resolution on a metropolitan railway network. Transportation Research Part B: Methodological, 45(2): 409-429. https://doi.org/10.1016/j.trb.2010.08.001

[28] Warfield, J.N. (1973). Binary matrices in system modeling. IEEE Transactions on Systems, Man, and Cybernetics, 3(5): 441-449. https://doi.org/10.1109/TSMC.1973.4309270

[29] Nagai, M., Tsai, C.P. (2013). Matrix based interpretative structural modeling. International Journal of Kansei Information, 4(3): 159-174.

[30] Liu, P., Li, Q., Bian, J., Song, L., Xiahou, X. (2018). Using interpretative structural modeling to identify critical success factors for safety management in subway construction: A china study. International Journal of Environmental Research and Public Health, 15(7): 1359. https://doi.org/10.3390/ijerph15071359 